\title{
Associated Behavioral Risks in a Group of Women During Pregnancy from Mures District
} \author{
Tarcea Monica ${ }^{1}$

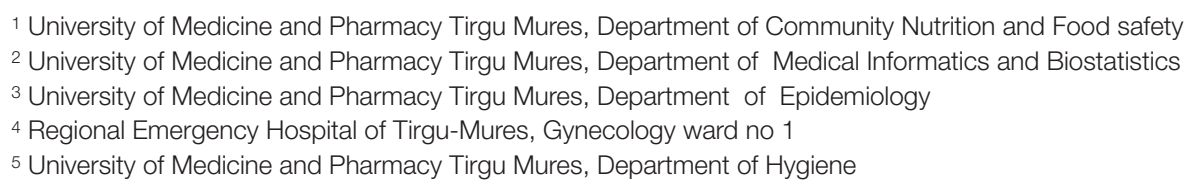

Ruța Florina1 ${ }^{1}$ Avram Călin², Voidăzan Septimiu ${ }^{3}$, Rus Victoria ${ }^{1 *}$, Georgescu Mihai ${ }^{4}$, Abram Zoltan $^{5}$,

Background. It is well-known that the exposure during pregnancy to lifestyle risk factors can affect thehealth both for the mother and the fetus. There are many risk factors for pregnancy, including: smoking, alcohol consumption, sedentary pattern, irregular daily meal serving plan, lack of knowledge regarding health prevention. The main objective of our study was to assess the practices, knowledge and attitudes towards lifestyle risk behaviors during pregnancy in a group of women from Tirgu-Mures area. Materials and methods. We used a cross-sectional study based on a questionnaire, assessingsmoking behavior and lifestyle patterns during pregnancy, on a group of 481 women from the urban area (58.84\%), as well as from the rural area (41.16\%) from Mures county. Results. In the study group, 190 women (39.5\%) used to smoke before pregnancy; among which $37.36 \%$ continued to smoke even after they found out they are pregnant. In the group of pregnant women that continued to smoke during pregnancy, we have studied other behavioral factors related to lifestyle, identifying the following: $5,73 \%$ have been consuming alcohol weekly, 56.33\% reduced greatly their physical activity level, 3.63\% have been consuming at least 3 cups of coffee a day. During pregnancy, $12.72 \%$ did not have a regular, daily meal serving plan, and $67.26 \%$ was a little or not at all concerned about their eating habits. Only $30.9 \%$ from the smoking pregnant women group have received information from the family doctor (GP) regarding the risk factors of smoking habits, while $38.18 \%$ did not receive any information. Conclusions. Behavioral risk factors in pregnancy have to be followed closely by the HealthCare System in order to avoid complications for the mother and the child. The best way of accomplishing that is through an efficient community intervention.

Keywords: pregnancy; smoking; lifestyle; community intervention

Received: 9 December 2014 / Accepted: 19 July 2015

\section{Introduction}

The presence of risk factors during pregnancy, factors that are linked to the lifestyle (e.g. smoking, alcohol consumption, sedentary pattern, not following a regular meal plan) represent a well-known threat to the health of the mother and fetus.

On the global scale, smoking is considered to be the cause of 6 million deaths per year, number that is estimated to increase to 8.3 million by 2030 [1]. Smoking cessation, at any age, results in lowering the morbidity risk and infant mortality risk $[2,3]$.

Smoking during pregnancy represents a phenomenon, influenced by a series of factors, as the socioeconomic, sociocultural and psycho-social factors [4]. It has been considered a major public health issue [5], representing one of the few factors with high preventability.

The toxic effect of tobacco is associated to complications during pregnancy, giving birth to a dead child, low weight at delivery, premature birth, along with other serious implications on the long term health for the mother, as well as for the child. Smoking during pregnancy has a downward

* Correspondence to: Victoria Rus

E-mail: victoria.stere@yahoo.com trend in the countries with a high income, but it is strongly associated with poverty in the countries with medium incomes $[5,6]$.

The teratogenic effect of alcohol is also notorious, alcohol consumption during pre-natal period being an important cause of illness for the future mother, a cause for congenital malformations and of development deficit for the newborn [7].

As regarding the physical activity level during pregnancy, the Department of Health and Human Services (DHHS) of the United Stated [8], recommends at least $150 \mathrm{~min}$ utes of moderate physical activity every week, expressed by aerobic exercises. For sports women, in the time anterior to the pregnancy, it is recommended to continue practicing sport, providing that the length and the intensity of the exercises are adapted according to the progress of the pregnancy and as it was recommended by the specialized doctor. This should not be a threat for the health of the mother and the baby [8].

Other studies have described coffee consumption during pregnancy as being a risk factor, directly associated to miscarriage and low weight at birth, for a daily consumption of $300 \mathrm{mg}$. $[9,10]$. 
Beside the lifestyle risk factors described so far, the nutrition behavior can become a risk factor for the health of the pregnant woman, unless she meets the optimal nutritional needs, quantitative, qualitative and by respecting a daily routine for meals. Either in pregnancy, or in the time preparing for a pregnancy, the nutritional recommendations for women are the same that is to wisely choose foods based on essential criteria - the nutrient content with a high biological value and an appropriate caloric intake [11].

A good management of all those behavioral factors of lifestyle requires the provision of information for educational purposes and for health, at a population level, optimizing the interventions of fighting against the risk factors with a negative influence on women of a fertile age, through the exposing that the second generation's health is threatened to.

For this purpose, we consider that it is important to know the degree of exposure to smoking during pregnancy, mainly of those in our area, in association with other risk factors with a high potential of being modified (alcohol consumption, sedentary lifestyle and coffee consumption), and the evaluation of the concern that women have for nutrition and the degree in which they received information from the physician regarding the lifestyle.

The purpose of the present study was to evaluate the behavior toward smoking during pregnancy, in Mures County, and also the behavior regarding alcohol consumption, regular physical activity, coffee consumption, the attitude toward diet and the degree in which pregnant women from the group have received information regarding the consequences of exposing to the behavioral risk factors.

\section{Methods}

We have performed a cross sectional study, in OctoberNovember of 2014.

\section{Data collection}

The study has included a sample of 481 pregnant women, hospitalized inthree maternity hospitals from Mures county.

They were interviewed based on a questionnaire, in order to evaluate the behavioral risk factors of lifestyle during pregnancy, questionnaire administration was performed on the basis of sampling convenience.All study participants were surveyed through interviewer's direct participation. The questionnaire was divided into several categories following aspects of smoking during pregnancy, socio-demographics, behavioral aspects in lifestyle sphere (alcohol, physical activity, coffee consumption, nutrition). In all three maternities of Targu Mures County annually are hospitalized, on average, approximately 3500 recently given birth mothers. During the period of questionnaire application, we interviewed 481 subjects, from a total of 600 recently given birth mothers hospitalized in that period. The difference is the result of a refusal rate of approximately $20 \%$ patients. This value of refusal rate is due to situations where the patients refused to be questioned, the patients could not be interviewed because of health problems or the interviewer was not present every time when the interviewing would have been possible for patients.

The questions were open type, closed type with ordered responses, most of them closed with unordered answers and binary questions, with a maximum time necessary to complete of 20 minutes. In the questionnaire header the patient was informed about the study purpose, anonymity and confidentiality of responses.

\section{Statistical analysis}

The information obtained from the questionnaire was gathered in anAccess data base, and the statistical analysis was performed using the IBM SPSS Statistics Base Authorized User V 22 Program. In order to analyses the category variables expressed by numbers (\%), we have used the chisquare test. The statistical significance was considered for the p-values lower than 0.005 .

\section{Results}

In the studied group, from the 481 women more than half were from the urban area $(58.84 \%)$, while $41.16 \%$ was represented by women coming from the rural area of Mures County. The age average was 29 years old (minimum was 14 years and maximum age 50 years).

In the first stage of the study, we followed the behavior towards smoking ofthe women from the sample group, and we have identified 190 (39.5\%) women that have smoked before. $37,36 \%$ of those $(\mathrm{N}=71)$ have continued to smoke even after finding out about the pregnancy. In the rest of the study we focused on identifying other behavioral risk factor among smoking women, compared to the presence of the same factors among women who have ceased smoking after finding out about the pregnancy. The percentage of women who consumed tobacco during pregnancy, included in the total study group was about $15 \%$.

In table 1 we present the result of an univariate analysis, highlighting how the analyzed risk factors influences the continuation of smoking in pregnant women. Weekly alcohol consumption during pregnancy has been identified in $9 \%$ of smokers women before pregnancy. Of those that are consuming coffee in a higher quantity than 2 cups a day, most of them have continued to smoke $(78.87 \%)$ while from pregnant women with low physical activity during pregnancy, a high percentage $(75.73 \%)$ had given up smoking. Based on the quantification of the answers given by the subjects, we have identified that $40,52 \%$ of smokers before pregnancy received poor information concerning the lifestyle risk factors and from these the majority have continued to smoke $(57.74 \%)$. Data related to attitude towards dietrevealed that among those with low concern towards diet, more than half continued to smoke (figure1).

Socio-demographic analysis showed that from below high school educated women, $87.32 \%$ continued smoking 
Table I. The influence of risk factors from pregnancy on brfore pregnancy smoker pacients

\begin{tabular}{|c|c|c|c|c|}
\hline \multirow[b]{2}{*}{$n=190$} & \multicolumn{3}{|c|}{ Smoking status, n $(39, \%)$} & \multirow[b]{2}{*}{$P$ value } \\
\hline & $\begin{array}{l}\text { Before } \\
\text { pregnancy } \\
\text { smokers, } \\
n=190\end{array}$ & $\begin{array}{l}\text { Pregnancy } \\
\text { smokers, } \\
n=71\end{array}$ & $\begin{array}{l}\text { Quitters, } \\
n=119\end{array}$ & \\
\hline $\begin{array}{l}\text { Weekly alcohol } \\
\text { consumption }\end{array}$ & $9(4,73 \%)$ & $4(5,63 \%)$ & $5(4,2 \%)$ & $p>0,05$ \\
\hline $\begin{array}{l}\text { Low physical } \\
\text { activity }\end{array}$ & $165(86,84 \%)$ & $\begin{array}{c}75 \\
(56,33 \%)\end{array}$ & $\begin{array}{c}90 \\
(75,63 \%)\end{array}$ & $p>0,05$ \\
\hline $\begin{array}{c}\text { Coffee intake }>2 \\
\text { cups }\end{array}$ & $118(62,1 \%)$ & $\begin{array}{c}56 \\
(78,87 \%)\end{array}$ & $62(52,1 \%)$ & $p>0,05$ \\
\hline $\begin{array}{c}\text { Lack of lifestyle } \\
\text { information from } \\
\text { the GP }\end{array}$ & $77(40,52 \%)$ & $\begin{array}{c}41 \\
(57,74 \%)\end{array}$ & $\begin{array}{c}36 \\
(30,25 \%)\end{array}$ & $p=0,05$ \\
\hline $\begin{array}{l}\text { Low concern about } \\
\text { nutrition }\end{array}$ & $101(53,15 \%)$ & $\begin{array}{c}56 \\
(78,87 \%)\end{array}$ & $\begin{array}{c}45 \\
(37,81 \%)\end{array}$ & $p=0,002$ \\
\hline $\begin{array}{l}\text { Education below } \\
\text { level ofhigh school }\end{array}$ & $101(53,15 \%)$ & $\begin{array}{c}62 \\
(87,32 \%)\end{array}$ & $\begin{array}{c}39 \\
(32,77 \%)\end{array}$ & $p=0,0001$ \\
\hline $\begin{array}{l}\text { Family income } \\
\text { under } 100 \text { euros/ } \\
\text { month }\end{array}$ & $84(44,21 \%)$ & $\begin{array}{c}54 \\
(76,05 \%)\end{array}$ & $\begin{array}{c}30 \\
(25,21 \%)\end{array}$ & $p=0.0001$ \\
\hline Housewife & $65(34,21 \%)$ & $\begin{array}{c}44 \\
(61,97 \%)\end{array}$ & $\begin{array}{c}21 \\
(17,64 \%)\end{array}$ & $p=0,0001$ \\
\hline Live in rural area & 76 (40\%) & $\begin{array}{c}41 \\
(57,74 \%)\end{array}$ & $\begin{array}{c}35 \\
(29,41 \%)\end{array}$ & $p=0,0001$ \\
\hline Unmarried & $61(32,10 \%)$ & $\begin{array}{c}41 \\
(57,74 \%)\end{array}$ & $\begin{array}{c}20 \\
(16,88 \%)\end{array}$ & $p=0,0001$ \\
\hline Rroma ethnicity & $34(17,89 \%)$ & $\begin{array}{c}28 \\
(39,43 \%)\end{array}$ & $6(5,04 \%)$ & $p=0,0001$ \\
\hline
\end{tabular}

in pregnancy while $32.77 \%$ have quit smoking $(\mathrm{p}<0.05)$ and from the housewives were identified $61.97 \%$ which continued smoking $(\mathrm{p}<0.005)$.In low-income families, percentage of those who gave up smoking when they found out about the pregnancy was lower $(25.21 \%)$ than those who continued smoking during pregnancy $(25.21 \%)$ $(p<0.005)$. Among smokers before pregnancy, 32.1\% were unmarried and $57.74 \%$ of them smoked during pregnancy $(\mathrm{p}<0.005)$. The dropout rate of smoking among rural women was lower $(29.41 \%)$ and the share of the rural women who continued to smoke was $57.74 \%$ ( $\mathrm{p}<0.005)$. Another analyzed variable was that of ethnicity, the results indicating a lower dropout rate among rroma pregnants $(5.04 \%)$ while $39.43 \%$ of them continued tobacco use in pregnancy $(\mathrm{p}<0.005)$.

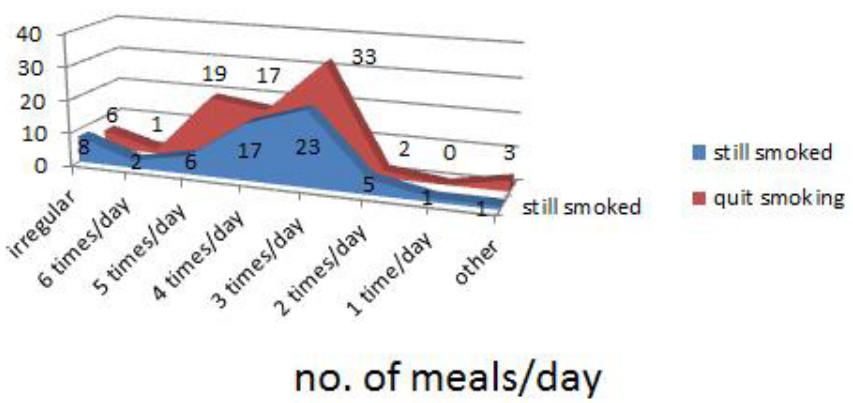

Fig. 1. Daily schedule of smoking women and ex-smokers
Table II. Multivariate association between the behavioral risk factors and socio-demographic factors, attitudes towards smoking and other factors

\begin{tabular}{|c|c|c|c|c|}
\hline \multirow{3}{*}{$\begin{array}{c}\mathrm{n}=190 \\
\begin{array}{c}\text { Alcohol consump- } \\
\text { tion during preg- } \\
\text { nancy }\end{array}\end{array}$} & \multicolumn{3}{|c|}{ Smoking status, n (\%) } & \multirow{3}{*}{$\begin{array}{l}P \text { value } \\
p=0,001\end{array}$} \\
\hline & \multirow{2}{*}{$\begin{array}{c}\mathrm{OR}^{*} \\
1,2\end{array}$} & \multicolumn{2}{|c|}{ Confidence intervals } & \\
\hline & & 0,1 & 5,2 & \\
\hline $\begin{array}{l}\text { Low physical } \\
\text { activity }\end{array}$ & 0,5 & 0,18 & 1,36 & $p>0,05$ \\
\hline $\begin{array}{c}\text { Coffee intake }>2 \\
\text { cups }\end{array}$ & 1,3 & 1,1 & 2,29 & $\mathrm{p}=0,01$ \\
\hline $\begin{array}{c}\text { Lack of lifestyle } \\
\text { information from } \\
\text { the GP }\end{array}$ & 1 & 1 & 2 & $\mathrm{p}=0,05$ \\
\hline $\begin{array}{l}\text { Low concern about } \\
\text { nutrition }\end{array}$ & 2,34 & 1,25 & 4,38 & 0,0077 \\
\hline $\begin{array}{l}\text { Education below } \\
\text { level of high school }\end{array}$ & 1,92 & 1,5 & 5,19 & $p>0,05$ \\
\hline $\begin{array}{l}\text { Family income } \\
\text { under } 100 \text { euros/ } \\
\text { month }\end{array}$ & 1,32 & 0,49 & 3,58 & $p>0,05$ \\
\hline Housewife & 1,95 & 0,84 & 4,49 & $p>0,05$ \\
\hline Live in rural area & 1,28 & 0,62 & 2,65 & $p>0,05$ \\
\hline Unmarried & 1,67 & 0,73 & 3,78 & $p>0,05$ \\
\hline Roma ethnicity & 3,66 & 1,17 & 11,41 & 0,0251 \\
\hline
\end{tabular}

* dependent variable (smokers before pregnancy) taken binary, 1- smokers in pregnancy; 0 - those who quit

For the data from Table II we applied a multivariate analysis to identify how the multitude of risk factors from lifestyle sphere and socio-demographic influences the patient to continue smoking on the gestational period. We identified significant values for lack of information from health professionals, lack of interest for nutrition, low level of education, low family income, lack of employment, rural origin, marital status (unmarried) and ethnic group, which influenced the smokers prior pregnancy to continue smoking during it.

\section{Discussions}

Adopting a healthy lifestyle by the women of a fertile age will assure the health of the future mother and will create a proper environment for future pregnancies, so necessary to the optimal development of the fetus. Recent studies have shown that smoking, alcohol consumption and coffee intake during pregnancy threats the health of the mother and the child [7].

Smoking in pregnancy is the main risk factor that can be modified, and that threats the maternal-fetal health. It was estimated that daily exposure to active smoking is, currently, the cause of 5 million deaths per year, worldwide [12], number that is estimated to rise to 10 million deaths by 2020 [13]. A representative study, performed in Romania, by the Ministry of Health, showed that in 2003, at a national level, $27 \%$ of the women between $15-44$ years were smokers [14]. 
The most recent data regarding smoking in Romania are provided by a study of the Ministry of Health, from 2011, Global Adult Tobacco Survey (GATS), that shows a smoking rate of $26.7 \%$ (4.85 million inhabitants) in the adult population. The prevalence was higher among men than among women $(37.45 \%$ vs. $16.7 \%)$. From the total of declared smokers, $24.3 \%$ are daily smokers $(34.9 \%$ among men and $14.5 \%$ among women), and $2.4 \%$ are occasional smokers (2.5\% men and $2.2 \%$ among women) [15]. The study targeted the adult and young population, without including the segment that represents the pregnant women.

Regional Romanian studies, has been reported a smoking rate of $24 \%$ among pregnant women, following a study on a sample of 160 pregnant women, hospitalized in 3 maternity hospitals from Bucharest [16], while another study from a different city of Romania, Brasov, on a larger sample of subjects $(\mathrm{N}=23139)$ estimated the same smoking rate of $24 \%$ in pregnancy [17]. In 2008, the study performed by Meghea et al, with women of $18+$ women, hospitalized in 2 clinics in Cluj-Napoca, has shown that $26 \%$ of the subjects smoked before pregnancy, but ceased smoking during pregnancy, while $15 \%$ of them continued to smoke during pregnancy [18].

By comparison, a study performed in Poland, on a sample group of 136 pregnant women, has identified a smoking rate of $25-30 \%$. The rate increased to $33-41 \%$ after measuring the cotinine level from the saliva [19].

Also, in the project „Increasing Capacity for Tobacco Research in Hungary", 2008-2013, the percentage of women that reported not to have ceased smoking after finding about pregnancy was $26.13 \%$ [20].

Pregnancy represents an ideal moment to cease smoking, considering that $20-45 \%$ of the smoking women cease to smoke when finding out they are pregnant [21].

Our study, performed on 481 subjects, has highlighted a $14.76 \%$ prevalence for smoking during pregnancy, value close to the one obtained by Meghea et al [18], but we included in the study the analysis of other behavioral risk factors and socio-demographic factors.

Among them stand out: coffee consumption as a factor of influence on the smoking ongoing, and mentioned in other studies that is appreciated by women especially in the socialization context and development of interpersonal relationships [7].

Low levels of education and lack of information received through health service providers are added to the risk factors list which favors the continuing of smoking in pregnancy.

Attitudes towards food intake both quantitatively and qualitatively but also in terms of respecting a schedule of serving meals showed a link with attitudes toward smoking by thefact that the concerned women to a greater extent of healthy lifestyle through nutrition are those who abandoned smoking with the appearance pregnancy.

We also highlighted a great influence of socio-demographic factors, meaning that socio-demographic dis- advantage is inversely related to smoking cessation. The percentage of women who quit smoking is lower among disadvantaged socio-economic class, most women belonging to this category continue smoking in pregnancy.

The difference between the values we obtained, compared to similar studies performed in other European countries comes from the fact that our sample is not representative at a national level, including only the newborn moms hospitalized in the three main maternities from Mures area.

As regarding the other behavioral factors with potential of being modified and that can do harm the health of the mother and child, the consumption of alcohol and coffee, the negligence towards the diet, the lack of sufficient knowledge for protecting the health, were more frequent reported among pregnant women that did not cease smoking during pregnancy, compared to those who smoked only before pregnancy ante ceased smoking during pregnancy. As regarding the lowering of the physical activity level and the attitude towards activity, the situation in the smoking group was similar to the one in the group of ex-smokers.

Actuality of the approached subject is maintained as long as smoking rates in pregnant women is high and continues to threaten the maternal-fetal health. Knowing the magnitude of this phenomenon and its variations over time can optimize interventional programs to combat the most important preventable risk factor for maternal and child health but also for the other associated risk factors by interventional measures adapted to these associations and socio-demographic conditions favoring the phenomenon studied.

Because the risk factors were more frequent among the smoking women, we consider that a global management of the risk behavior should be adopted, rather that isolated measures for one or more risk factors. For a better evaluation of the prevalence of risk factors during pregnancy, we consider it is necessary to extend the study in our area, to a higher number of women, and also in other areas of our country, through a national project of evaluating the risk behavior during pregnancy. Those studies can be the starting point for the community interventions for fighting the risk factors that threat the health of the mother and child.

\section{Conclusions}

Due to the high potential of preventability of all the risk factors linked to lifestyle, that were identified in our study, the role of informing the young women, that prepare themselves to become mothers, must make a priority come-back in the health care provider's agenda, through the general practitioners, midwifes or nutritionists and dieticians, in order to avoid complications and to maintain the health of the mother and fetus. It is a real challenge for the individual, the family and the society as well, to find the best methods of community intervention in order to reduce risks factors of lifestyle. 


\section{Aknowledgement}

This paper is supported by the Sectorial Operational Programme Human Resources Development (SOP HRD), financed from the European Social Fund and by the Romanian Government under the contract number POSDRU/159/1.5/S/133377/

\section{References}

1. World Health Organization. Tobacco Factsheet, 2011, available at http://www.who.int/mediacentre/factsheets/fs339/en/

2. Doll R, Petro R, Boreham J, Sutherland I. Mortality in relation to smoking: 50 years' observation on male British doctors; Br Med J, 2004;328:1519

3. Bjarveit $\mathrm{K}$, Tverdal A. Health consequences of sustained smoking cessation; Tobacco control, 2009, 118: 197-205.

4. Borlan T, Babauan A, Irfan S, Schwartz R. Exploring the adequacy of smoking cessation support for pregnant and postpartum women; BMC Public Health, 2013;13:472.

5. Tong VT, Jones JR, Dietz PM, et al. Trends in smoking before, during and after pregnancy- Pregnancy risks Assessment Monitoring System (PRAMS), United States, MMWR, 2000-2005, 58:1-29.

6. Berlin I, Grange G, Jacob N, Tanguy ML. Nicotine patches in pregnant smokers: randomized placebo controlled, multicenter trial of efficacy; BMJ, 2014;348:1622.

7. Lassi ZS, Imam AM, Dean SV, Bhutta Z. Preconception care: caffeine, smoking, alcohol, drugs and other environmental chemical/radiation exposure; Reprod Health, 2014;11:S6.

8. U.S. Department of Health and Human Services. ODPHP Publication no UOO36, Washington, DC, USA; 2008. Physical Activity Guidelines for Americans. http://www.health.gov/PAGuidelines/

9. Chen LW, Wu Y, Neelakantan N, et al. Maternal caffeine intake during pregnancy is associated with risk of low birth weight: a systematic review and dose response meta-analysis; BMC Med, 2014;12:174.

10. Tolstrup JS, Kjaer SK, Munk C, et al. Does caffeine and alcohol intake before pregnancy predict the occurrence of spontaneous abortion?, Human Reproduction, 2003;18:2704.

11. Duffy RL. - American Dietetic Association Complete Food and Nutrition Guide; Ed. John Wiley \& Sons, USA, 2012.

12. Athabe F, Aleman A, Mazzoni A, et al. Tabacco cessation intervention for pregnant women in Argentina andUruaguay: study protocol; Reprod Health, 2013;10:44.

13. World Health Organization: World Health Report 2002. Geneva, 2002.

14. Ministry of Health-Smoking and Public health in Romania. Knowledge, attitudes and practices regarding tobacco use among general population in Romania, 2004. Available at: http://www.ms.ro/fisiere/ pagini_virtuale/94_94_Fumatul_si_sanatatea_publica_in_Romania.pdf

15. Ministry of Health - Global Adult Tobacco Survey (GATS), 2011. Available at: http://www.who.int/tobacco/surveillance/en_tfi_china_ gats_factsheet_2010.pdf

16. Munteanu I, Trenchea M, Puscoiu C, Mihaltan F. Smoking prevalence of pregnant women in Romania: smoking effects on newborns; CHESTI, 2007;132-256.

17. Moga M, Preda G. Smoking in pregnancy; JEPE, 2008;9:566-73.

18. Meghea C, Rus D. et al. Smoking during pregnancy and associated risk factors in a sample of Romanian women, European J Public Health, 2010;22:229-253

19. Polanska K, Hanke V, Sobala W, Juerwicz J. Exposure to tobacco smoke of pregnant women-results of prospective study in Lodz region; Przegl Lek, 2007;64:824-826.

20. Peter B, Foley K, Fogarasi-Grenczer A. - Increasing Capacity for Tobacco Research in Hungary; Institute for the History of Hungarian Science, Budapest, 2013.

21. Nguyen S, Von Kohorn I. - The importance of social networks on smoking: perspectives of women who quit smoking during pregnancy; Matern Child Health J, 2012:16: 1312-1318. 